\title{
AN EXPERIMENTAL ANALYSIS OF THE BEHAVIOUR OF LITTORINA LITTOREA (L.) UNDER NATURAL CONDITIONS AND IN THE LABORATORY
}

\author{
By G. E. Newell \\ Queen Mary College, University of London
}

(With Text-figs. I-Io)

The previous paper (Newell, I958) was mainly an account of straightforward observations of the winkle population on the shore at Whitstable. These suggested additional work on the activities of the animals, particularly their responses to light and to gravity, which are important in the maintenance of their position on the beach.

\section{RESPONSES TO SUNLIGHT ON THE BEACH}

The fact that individual tracks in the sand seem to follow an apparently orientated course suggests that winkles are reacting to visual clues, since the terrain is flat and featureless. To test this supposition a winkle crawling from east to west with the sun on its left-hand side was shaded from the sun by a piece of cardboard. Then the image of the sun was shone on its right-hand side by means of a plane mirror. Immediately the winkle changed direction and crawled back on a track parallel to its original course. This experiment was repeated with several other specimens, some of which were moving from approximately north to south and in various other directions, but with the invariable result that their direction of crawling was reversed when the apparent direction of the light was altered. A slightly different experiment was one in which winkles were lifted from the sand and placed on a moist plate. Most began crawling in more or less straight lines and when the plate was turned through I 80 degrees the direction of crawling was reversed, each winkle countermarching approximately along its original path.

These results seem to show that winkles crawling on wet sand are orientating to the direction of the sun in a manner which seems likely to be a 'light-compass reaction' (Fraenkel \& Gunn, I940), since, whilst individuals pursue an orientated course for some time, yet the direction of crawling is capable of reversal and, moreover, there is a good deal of variation in the direction of movement as between individual winkles. The maze of trails in the sand, despite the statement of Schwarz (1932), gives no immediate impression of 
constancy of direction for the population as a whole and the discovery that each trail is, in fact, a record of orientated crawling was made possible only because attention was focused on small instead of large samples of animals. Nevertheless, it does not follow that there is no pattern of orientation for all the winkle trails even if it is not at first sight obvious.

A survey made at 13.30 to $\mathrm{I} 4.30 \mathrm{~h}$ on $\mathrm{I} 4$ October at the time of low water, roughly $4 \mathrm{~h}$ after the tide had uncovered the area, showed the usual maze of tracks in the sand, but only a few winkles were still crawling. The bearing of I25 of these tracks was measured to the nearest ro degrees (magnetic) by means of a prismatic compass and the results are given in the form of a polar diagram (Fig. IA). From this it is at once obvious that the majority of tracks are approximately towards and away from the sun but that there is a good deal of variation and $15 \%$, approximately, are at right angles to the sun's rays. It must be remembered, however, that the tracks are not all made at the same time even at one tidal level, and, as the tide recedes, the apparent motion of the sun will cause tracks on lower levels to differ in direction from those higher up the shore with the result that the records made on any survey will be expected to show some 'scatter'. Nevertheless, polar diagrams (Fig. I B-D) similar to that in Fig. I A, but made from tracks recorded at different times of the day and for different tides in the lunar cycle from neaps to springs, fully confirm the idea that winkles crawl mainly along the direction of the sun's rays, whilst observations as the tide recedes show that at first the direction of crawling is mainly towards the sun and later, mainly away from it. Fig. ID, although very similar to the three previous diagrams, was constructed from results obtained on a dull summer day and suggests, therefore, that the animals were orientating to the brightest patch in the sky. It remained possible, however, that the pattern of polarized light in the sky might be providing the visual cue to which the responses were made. To test this animals were completely shaded by a large sheet of 'Polaroid' which was rotated to varying degrees and the effect on the direction of crawling noted. Of fifty winkles tested in this way none showed any clear-cut alteration of the direction of movement, most of them continuing to crawl in the same direction as when they were fully exposed.

Similarly, winkles tested in the laboratory with a sheet of 'Polaroid' interposed between them and a $200 \mathrm{~W}$. lamp, also seemed not to orientate to the plane of polarization. These observations are, admittedly, insufficient to state definitely that winkles do not orientate to the plane of polarization but, even if further experiments show that this can affect their direction of crawling under laboratory conditions, it is unlikely that responses of this kind play any part in the lives of animals in natural conditions, a point of view clearly expressed by Stephens, Fingerman \& Brown (1953) in a discussion of the orientation mechanism of Drosophila. These authors also point out that, as expressed by Fresnel's Laws, at all angles of incidence except 0 and 90 degrees, 'light 
vibrating in the plane defined by the incident and reflected rays will be more efficiently refracted than light vibrating in a plane normal to this'. This applies even to light entering a non-birefringent medium, and so an apparent response to the plane of polarization of the light may be an indirect one, the animal in reality responding to the amount of light entering the eye.

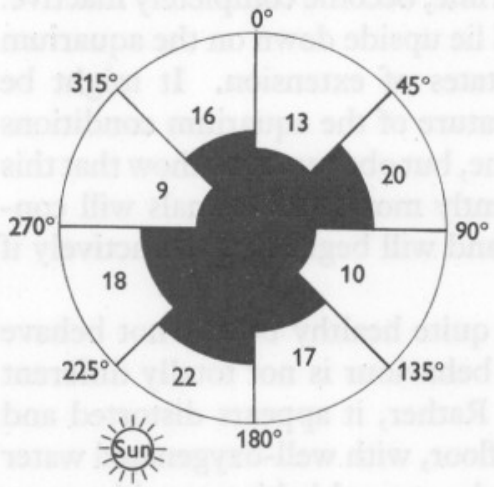

A

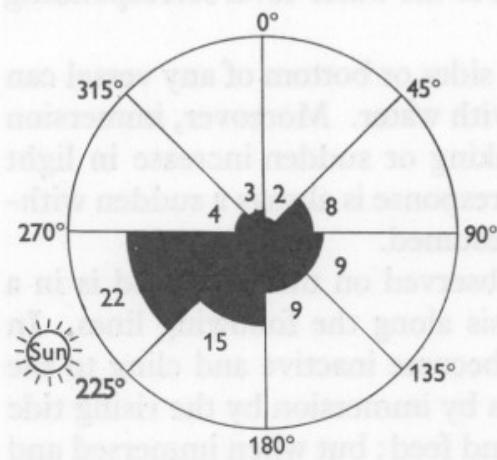

C

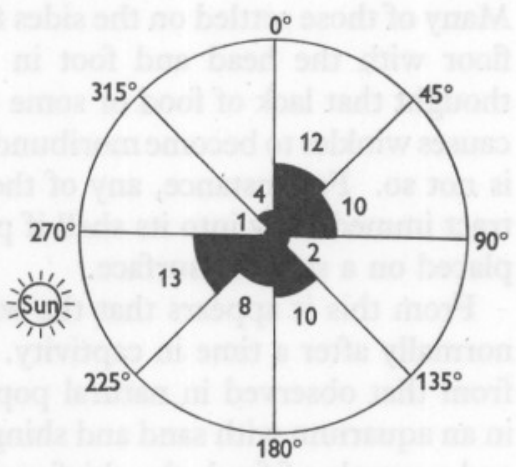

B

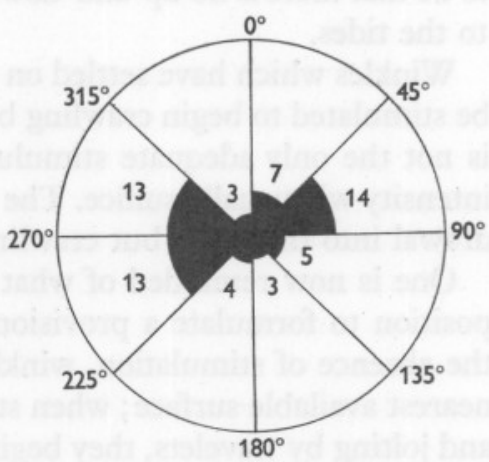

$\mathrm{D}$

Fig. I. Polar diagrams to show the directions of tracks and numbers of winkles moving along various tracks in the sand. Bearing measured to the nearest $10^{\circ}$ magnetic. (A) 14 October 1956, bright sunlight, low water, neap tides; (B) 25 March 1957, 5 h after low water, sun shining only occasionally between clouds; (C) 27 March 1957, I h after tide had receded from M.L.T., sun's disc showing through faint haze; (D) 3 I July 1957, low water, overcast sky, position of sun, $290^{\circ}$.

\section{BEHAVIOUR OF WINKLES IN AN AQUARIUM}

If winkles are collected at random from a variety of situations on the shore which include vertical, sloping and horizontal surfaces, their behaviour in an aquarium is also very variable. Soon after being tipped in, practically all of them begin to crawl about, but this activity is not continued indefinitely. After some hours of what appears to be random crawling, they settle down, 
some on the sides at varying heights relative to the water-level and some on the bottom. In these situations the vast majority remain motionless for hours or days but very occasionally one will become active and crawl about. Here again there is no uniformity in the direction of crawling.

After being kept in captivity for periods of 2 weeks or longer, all the winkles, even those which have settled below the waterline, become completely inactive. Many of those settled on the sides fall off and lie upside down on the aquarium floor with the head and foot in varying states of extension. It might be thought that lack of food or some adverse feature of the aquarium conditions causes winkles to become moribund after a time, but observations show that this is not so. For instance, any of these apparently moribund animals will contract immediately into its shell if picked up and will begin to crawl actively if placed on a suitable surface.

From this it appears that the winkles are quite healthy but do not behave normally after a time in captivity. Yet their behaviour is not totally different from that observed in natural populations. Rather, it appears distorted and in an aquarium with sand and shingle on the floor, with well-oxygenated water and a supply of food, the chief variant from the natural habitat would appear to be that there is no up-and-down oscillation of the water-level corresponding to the tides.

Winkles which have settled on the vertical sides or bottom of any vessel can be stimulated to begin crawling by filling it with water. Moreover, immersion is not the only adequate stimulus, since shaking or sudden increase in light intensity will usually suffice. The immediate response is always a sudden withdrawal into the shell, but crawling is soon resumed.

One is now reminded of what has been observed on the shore and is in a position to formulate a provisional hypothesis along the following lines. In the absence of stimulation, winkles tend to become inactive and cling to the nearest available surface; when stimulated, as by immersion by the rising tide and jolting by wavelets, they begin to crawl and feed; but when immersed and under uniform conditions they cease moving after a time and settle down. Clearly those on horizontal surfaces, and especially on wetter parts of the shore, will experience different conditions from those settled on groynes. The available evidence suggests that the stimulus to crawl on flat surfaces is an increase in light intensity and jogging by the breaking wavelets as the tide falls. Winkles on vertical surfaces are similarly activated but they are also induced to settle by desiccation, which in its extremer conditions causes withdrawal of the foot and adhesion solely by means of hardened mucus (Wilson, I929).

\section{REACTIONS TO GRAVITY}

So far, attention has been paid only to winkles crawling on the virtually horizontal surface of wet sand, but an appreciable proportion of the population lives, often densely aggregated, on the wooden groynes running at right angles 
to the shoreline from H.W.S. to a varying distance below H.W.N. Tracks made by the periodic feeding excursions are not easy to follow in these situations, but, as has been mentioned, on some groynes tracks can be seen to be made up of a downward, horizontal and upward limb. They thus resemble in general form those made on horizontal surfaces, but since winkles occur on either the west or east face of groynes, in light or in shade, it would seem unlikely that the movements are orientated solely with respect to light but rather that gravity provides the necessary directional stimulus.

A chance observation is of interest in this connexion and serves also to reinforce the idea that the clue to an understanding of the behaviour is to pay regard to individual winkles, taking note of the exact situation from which they were collected. A batch of winkles was collected from the top surfaces of flat stones and a similar batch from the vertical face of a groyne. Each batch was placed in a separate tin and after $2 \mathrm{~h}$ those from flat surfaces, without exception, were still at the bottom of the tin, whereas those from the groynes were settled on the sides of their tin, clear of the bottom. This shows that those from horizontal surfaces are indifferent to gravity, whereas those from vertical surfaces behave, at least for a time whilst in the dark, in a negatively geotactic fashion. This observation has been confirmed on six subsequent occasions. On one of these, namely on 26 September 1956 , the winkles were examined at intervals of $2,6,12,16$ and $72 \mathrm{~h}$. Those from vertical surfaces remained settled on the sides of the tin, whereas those from horizontal surfaces were all massed at the bottom. It remains to be seen if winkles from vertical surfaces are indifferent to the stimulus of directional light, but this can be tested only under laboratory conditions (p. 255).

As has been mentioned winkles react to the stimulus of gravity in a variable manner according to the slope of the position on which they have settled. It is this which accounts for variations in behaviour in an aquarium when animals are collected at random from the shore. To eliminate this variable, a batch of twelve winkles was taken from the strictly horizontal surfaces of flat stones left high and dry by the tide. Each animal was marked with a dab of yellow paint. A second batch was collected from the tops of flat stones in a pool of water and marked with blue paint whilst a third batch from vertical surfaces was marked with a spot of red paint. Each of these batches of twelve winkles was placed in an aquarium with sand and shingle in the bottom, the larger stones projecting above water-level. After crawling and feeding for some hours, all the animals settled down.

A summary of their subsequent movements is set out below, from which it will be seen that those collected from flat surfaces tended to settle in somewhat similar situations, irrespective of whether they were dry or not, whereas those from vertical surfaces tended to settle on the sides of the aquarium, i.e. on vertical surfaces. This confirms previous findings, viz. that the past history of a particular winkle influences its geotactic response. 
Twelve winkles from flat, dry stones, marked with yellow paint. None climbed up the tank in the first hour. After $2 \frac{1}{2} \mathrm{~h}$ four were on the sides at the surface film and the rest on stones lying on the bottom of the tank. After 3 days seven were on stones and five on the sides of the tank at the surface film.

Twelve winkles from flat, submerged stones, marked with blue paint. None climbed up the sides of the tank in the first hour. After $2 \frac{1}{2} \mathrm{~h}$ two were on the sides of the tank but below the waterline. After 3 days six were on stones, four were on the sides of the tank and two on the bottom.

Twelve winkles from vertical surfaces marked with red paint. Twelve climbed above the waterline in $6,8,9,11,14,15,17,22,24,25,25$ and 31 min respectively. After $2 \frac{1}{2} \mathrm{~h}$ eight animals had moved down and settled at the waterline, head uppermost. After 3 days, nine were settled on the sides and three were crawling on the bottom of the aquarium.

Results confirming those set out above were obtained by collecting winkles from the vertical faces of groynes and from the tops of flat stones and testing their geotactic responses in separate vessels. For example, twelve winkles from groynes were placed in a large bottle full of sea water. Six immediately crawled up and reached the top in $2 \mathrm{~min}$. They stayed there until accidentally dislodged. Three crawled up and settled on the sides but below the waterline within $2 \mathrm{~min}$, whilst after $2 \mathrm{~min}$ the remaining three were still crawling on the bottom. This experiment was made in diffuse light but essentially the same result was obtained in bright sunlight. Varying the direction of the light rays entering the bottle appeared to have no effect on the behaviour of the animals. The bottle was then put in complete darkness and after $2 \mathrm{~h}$ seven were at the top, two were on the sides but just below the waterline and three were on the bottom.

This seems to show that winkles from the sides of groynes are predominantly negatively geotactic; but subsequent observations show that this view, which accords with most previous workers, requires modification, for, as will be seen, under suitable conditions winkles reverse the sign of their response, and it is this reversal which accounts for the lack of a $100 \%$ uniformity in the previous experiment.

Twelve winkles collected from horizontal surfaces were placed in a small glass tank in diffuse light. All began to crawl but repeatedly turned as if unable to orientate. After $4 \mathrm{~h}$, although apparently random movements brought them into contact with the sides of the tank, none had climbed the walls. Thus, winkles from flat surfaces are not negatively geotactic, at least for some time. Yet, after $24 \mathrm{~h}$ in the tank all the winkles of this same batch had settled on the waterline.

It can, therefore, be assumed that all winkles have a tendency to climb and settle on vertical or steeply sloping surfaces, but that if this opportunity is denied them, the response becomes abolished for some time, which other experiments show may be as long as Io days. This seems to be a process of habituation as defined by Thorpe (1956). 


\section{GRAVITY REACTIONS OF WINKLES AFTER DRYING}

Bearing in mind that all winkles settled intertidally on vertical surfaces experience a semi-diurnal drying after the tide has receded, it seemed important to test if drying has any effect on the responses to gravity. Therefore, instead of beginning observations, as in previous experiments, as soon as possible after collecting the animals, time was allowed for them to dry.

Twelve winkles collected from groynes at the time of low water were left in a tin for 5 days. Then, three at a time, they were allowed to settle on a horizontal moist glass plate. This was then placed vertically in a large beaker of sea water. Immediately all the winkles began to crawl downwards. That is, contrary to previous occasions, they behaved positively geotactically. At levels of from 3 to $5 \mathrm{~cm}$ below the surface they moved about more or less horizontally and then crawled up to settle at or above the waterline. This was the invariable result and shows that after a period of desiccation winkles behave positively geotactically, are then neutral to the stimulus of gravity for a time and finally reverse the sign of their response. Light can be ruled out as an essential orientating stimulus since the experiments were carried out in diffuse light whilst exactly comparable results were obtained with light from directly above the beaker or shining through the sides.

Additional results are set out in tabular form (Table I).

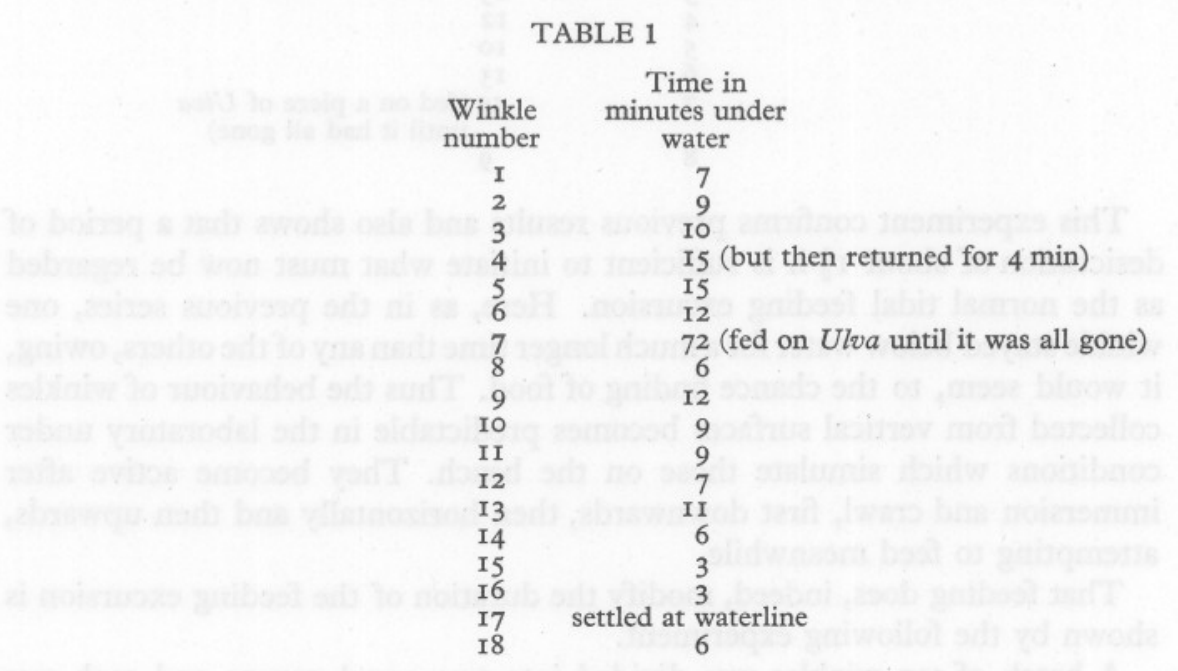

The results of the previous experiment have an obvious bearing on the interpretation of the behaviour of winkles under natural conditions on the beach groynes, since they clearly point to the conclusion that the animals settle down in the head-up position but become positively geotactic after a period of desiccation. This enables them to carry out feeding migrations 
when reached by the incoming tide. A reversal of the gravity response, so that its sign becomes negative, causes them to return approximately to the position they had left, when they settle down and later on experience yet another period of drying.... and so on. One is reminded of Mitsukuri's results on Littorina exigua (p. 259) which showed that this winkle also moves downshore after a period of desiccation, although Mitsukuri believed that this was because they became positively phototactic.

It was obviously of interest to repeat the previous experiment on winkles which had not been desiccated for a period of as long as 5 days. A summary of the results of a further series of tests is set out below.

Eight winkles were collected from the vertical face of a groyne at $09.00 \mathrm{~h}$ at approximately low water and allowed to settle on a moist glass plate at $10.30 \mathrm{~h}$. The plate was then placed vertically in a beaker of sea water in diffuse light. Each specimen moved down, then moved horizontally and finally returned to the waterline, the times for these migrations being as follows (Table 2).

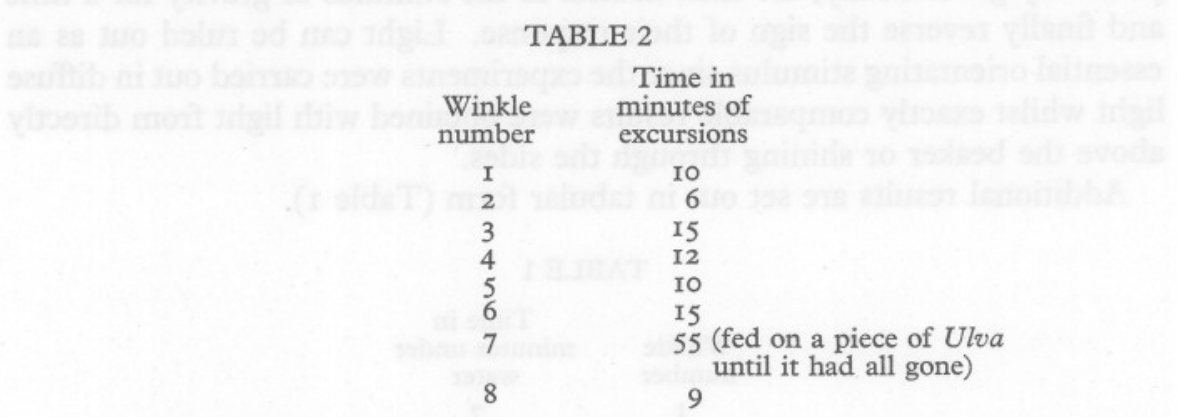

This experiment confirms previous results and also shows that a period of desiccation of about $\mathrm{I} \frac{1}{2} \mathrm{~h}$ is sufficient to initiate what must now be regarded as the normal tidal feeding excursion. Here, as in the previous series, one winkle stayed below water for a much longer time than any of the others, owing, it would seem, to the chance finding of food. Thus the behaviour of winkles collected from vertical surfaces becomes predictable in the laboratory under conditions which simulate those on the beach. They become active after immersion and crawl, first downwards, then horizontally and then upwards, attempting to feed meanwhile.

That feeding does, indeed, modify the duration of the feeding excursion is shown by the following experiment.

A batch of ten winkles was divided into two equal groups and each was placed in a tank with only $\mathrm{I} \mathrm{cm}$ water in the bottom. One batch was allowed to feed for $2 \mathrm{~h}$ on Ulva whilst the other batch was left unfed. Each batch was then immersed by running in sea water. The results are set out in Table 3 . This clearly shows that fed winkles are less active than unfed ones and that the presence of food prolongs the period of immersion. 
Fed

None moved at once. Four stayed immersed for $\mathrm{I} \frac{1}{2} \mathrm{~h}$. After $3 \mathrm{~h}$, four had climbed above the waterline but one remained below it still feeding.
TABLE 3

\section{Unfed}

All became active at once and all five crawled down, then horizontally and then up above the waterline in $45 \mathrm{~min}$.

Another experiment which gave a more clear-cut result was carried out on winkles which had been collected io days previously from a groyne. From these, two batches of five each were taken at random. One batch was allowed to feed on lettuce for $2 \mathrm{~h}$. The other batch had been starved during the ro days' captivity. Each batch was then allowed to settle on the sides of a jar with a little water in the bottom. All settled above the waterline. The experiment began when water was run into the jars so as to submerge all the winkles. The results are summarized below.

Fed winkles. All five animals were near the top of the jar. When submerged none became active for some minutes and none crawled about under the water. After $35 \mathrm{~min}$ all had crawled up out of the water.

Starved winkles. One winkle was near the top of the jar and four on the sides lower down. All became active immediately after immersion, crawled down, then horizontally and finally up above the waterline in times which varied from 7 to $38 \mathrm{~min}$.

This not only confirms the view that fed winkles are less active than starved ones, but shows also that feeding abolishes the positively geotactic behaviour which is always evoked by the immersion of starved winkles. The longer times of the feeding migrations of these winkles which had been starved for Io days, when compared with those carried out on animals kept in captivity for shorter periods suggest that the time spent in an attempt to feed is related to the degree of starvation.

The experiments described so far have indicated that the behaviour of winkles collected from the shore at Whitstable varies a good deal according to the situation on which the animals have come to rest, but observations on gravity responses have been chiefly on winkles collected from vertical surfaces. Comparable experiments on those from horizontal surfaces give different results, as is shown, for example, by those summarized below.

Twelve winkles were collected from the tops of flat stones at $09.00 \mathrm{~h}$ at low tide and were tested for gravity responses at II.30 h. Each winkle was placed on a moist glass plate. After settling, the plate was placed vertically in a beaker of sea water illuminated by diffuse light from a north window. Each winkle was, in the first instance, placed so that it was orientated transversely across the plate. Most stayed in this position but four re-orientated to assume the head-up position directly the plate was tipped up so that it looked like a mechanically caused slip, and three out of these four animals later orientated across the slope. Three slipped off the plate but none crawled up or down. 
These observations show that winkles from horizontal surfaces are, indeed, as has been suggested by previous experiments, indifferent to the stimulus of gravity.

So far the gravity reactions of winkles have been tested only in response to strictly defined surfaces, but on rocky shores winkles will experience slopes intermediate between the horizontal and the vertical. It is, therefore, of interest to find the minimum slopes which will evoke geotactic responses. This was done by placing winkles on horizontal surfaces and then tilting up the plate, Io degrees at a time. As has already been seen, winkles from horizontal surfaces pay no regard to the stimulus of gravity and so only animals from groynes were tested in this manner. Several experiments of this nature were carried out. Practical difficulties arise. For example, not all the winkles used adhere to the plate and so some fall off when the plate is tipped at angles of 40 degrees to the horizontal or greater; some settle down and adhere but fail to crawl; others crawl horizontally and then off the plate and up the sides of the containing vessel.

Twelve winkles collected from groynes at time of low water were placed on a wooden plate with their heads downwards in diffuse light. The plate was then tipped up ro degrees at a time and left on each occasion for $2 \mathrm{~min}$. The minimum angle at which any winkles orientated to the head-up position was Io degrees.

Twelve winkles collected from groynes at low water were placed with the longitudinal axis across the plate which was then tipped up, Io degrees at a time. The plate was kept moist but was not immersed in water. From Table 4 it will be seen that at the lower angles winkles tended to retain the orientation at which they were placed on the plate, but that at 90 degrees all twelve assumed the head-up position, either statically or by crawling up.

TABLE 4

$\begin{array}{cccc}\begin{array}{c}\text { Angle } \\ \text { (degrees) }\end{array} & \text { Up } & \text { Down } & \text { Horizontal } \\ \text { I0 } & 3 & 2 & 7 \\ 20 & 3 & 4 & 5 \\ 30 & 2 & 3 & 7 \\ 40 & 3 & 3 & 6 \\ 50 & 2 & 2 & 8 \\ 60 & 2 & 0 & 10 \\ 65 & 7 & 0 & 5 \\ 70 & 7 & 1 & 4 \\ 80 & \text { Orientation } & 1 \\ 90 & 12 & 0 & 0\end{array}$

All that can be inferred from the results is that the minimum slope to which winkles can orientate is probably about 10-20 degrees, that at slopes of $60-65$ degrees most of them assume the head-up position and that at 90 degrees all winkles orientate head-uppermost. This is rather different from saying 
that at steep angles winkles tend to behave in a negatively geotactic fashion, since many animals remained in the same position although re-orientating with respect to gravity. Indeed, in other experiments some of the more active specimens crawled right to the top of the vessel and then over the top and downzwards on the outside surface.

Attempts by previous workers, as for example Kanda (1916), to assess the strength and nature of the response of winkles to gravitational stimuli gave conflicting results, and from what has been said it will be realized that this can be attributed to two main causes. In part it could have been due to a failure to appreciate that winkles collected from steeply sloping surfaces normally alter the sign of their response to gravity after crawling for some time, so that intermittent observations might catch a winkle during its downward, horizontal or upward phase of movement. It is also true that previous workers paid insufficient attention to the exact situation from which winkles were collected, so that those from sloping surfaces were mixed with those from horizontal ones, when, of course, a variety of responses was detected. Gowanloch \& Hayes (1926) showed that, statistically, winkles from higher levels on the shore tended to crawl upwards more strongly than those from lower levels, the implication being that in some way this difference in behaviour was related to the position on the shore, but they paid no regard to the winkles as individuals. It seems likely, however, that the differences they noted are due, not to a difference in shore levels or zones as such, nor to time of exposure to air, etc., but, instead, to a difference in beach slope at various positions relative to tide marks. I am indebted to $\mathrm{Mr}$ Derek Mills for the information that at New Brunswick (where Gowanloch \& Hayes made their collections), the shore has a steep upper beach and a more or less horizontal rock platform near low water-level, so that the differences in behaviour with respect to the stimulus of gravity may be attributed to habituation to a horizontal or steeply sloping surface, such as has been noticed for the winkle population at Whitstable.

Summary of results of observations on the reactions of winkles to gravity

(I) Winkles have an inherent tendency to settle on vertical or steeply sloping surfaces, when they assume the head-up position.

(2) Provided that the surface is moist, when stimulated to crawl the animals move first downwards, then horizontally and then up again, to regain approximately their original position. Immersion in water, mechanical agitation or a sudden increase in light intensity are stimuli which are adequate to promote crawling.

(3) The excursions from the position of settlement can be regarded as feeding migrations.

(4) Winkles collected from horizontal surfaces are indifferent to gravitational 
stimuli for periods which vary from some hours to Io days. They have become habituated to flat surfaces but this habituation gradually diminishes, so that when presented with an opportunity to crawl upwards they revert to their inherent pattern of response.

(5) Fully fed winkles do not respond by crawling downwards when stimulated to move, but starved winkles make longer feeding excursions below water if they happen to find food.

(6) The minimum slope to which winkles orientate is about ro-20 degrees.

\section{REACTIONS TO LIGHT}

\section{Winkles collected from horizontal surfaces}

The following observations are a selection from very many which were made and serve to show that winkles from horizontal surfaces react to the stimulus of light in a way which is consistent with the form of the tracks seen on the sand at low tide.

Twelve winkles were taken from the tops of flat stones shortly before the incoming tide reached them but no note was taken of their exact orientation on the stones. The animals were placed in a shallow glass dish of sea water in bright sunlight, the sun being nearly due south.

The animals began to crawl almost at once. Seven crawled away from the sun and five towards it. Not all the paths were directly towards or away from the sun but any obliquity of the paths brought the winkles to the sides of the dish, when, of course, the paths of necessity became straight. After $3 \mathrm{~min}$ seven were at the end away from the sun and five at the end nearest the sun. After about $5 \mathrm{~min}$ three animals which had formerly been photopositive became photonegative and crawled to the opposite end of the dish, whilst the two which were photopositive became photonegative. This reversal of response was confirmed by turning the dish through 180 degrees, when the five winkles under consideration also turned round and maintained the same orientation to the sun's rays. This chance observation also confirms what had been seen only rarely on the beach but which had been inferred from the form of the tracks in the sand, viz. that winkles on flat surfaces reverse the sign of their response to light. From this it is also obvious that the immediate past history of an animal will modify the results obtained when testing its light reactions, and winkles collected at random from horizontal surfaces would not be expected to display any uniformity of orientation to light. Indeed, the result set out below is typical of many which were obtained even when winkles were collected from exactly similar situations.

Twelve winkles were collected from horizontal surfaces, all with their heads facing the sun, and placed in a shallow dish of sea water. Three behaved photopositively, three behaved photonegatively, and six moved across the sun's rays. 
The experiments, an account of which follows, were designed to test the reactions to light of winkles which had received uniform treatment for some time before the observations.

Eight winkles from horizontal surfaces were kept in a tin for $48 \mathrm{~h}$ and then placed in a shallow dish with the bottom and three sides covered by black paper. A beam of parallel light was shone through the uncovered end of the dish from a microscope lamp. Two winkles crawled towards the light; after 2 min two winkles crawled away from the light, four winkles crawled transversely; and after 6 min eight winkles crawled towards the light. This shows that unfed, dark-adapted winkles are positively phototactic, but that there is some variation in the initial direction of their crawling.

In order to record the paths followed by winkles crawling when illuminated by a parallel beam of light, animals which had been dark-adapted for 4 days were placed in a large developing dish whose walls were covered with black paper and which was floored with $\mathrm{cm}$ graph paper. Light beams from microscope lamps gave an illumination of $250 \mathrm{ft}$. candles at the floor of the dish and could be shone either at right angles or from opposite ends of the dish. The movements of the winkles were recorded at half-minute intervals on another piece of graph paper.

The selection of tracks which follow (Figs. 2-5) shows that all the winkles behaved positively phototactically but that when two lights were shone at right angles a crawling animal usually disregarded the second light and continued to crawl towards the first one. This suggests that they are behaving telotactically (Fraenkel \& Gunn, 1940), a type of behaviour which has much in common with light-compass reactions.

In a repeat of the above experiment twelve dark-adapted winkles collected from horizontal surfaces were placed in a dish of sea water lined by black paper. A beam of parallel light was shone in at one end. All were strongly photopositive for $\mathrm{I} 2 \mathrm{~min}$ but at times varying from $\mathrm{I} 2$ to $20 \mathrm{~min}$ they became photonegative. This, it will be realized, confirms observations made previously $(a)$ on the shore, and $(b)$ in a dish using the sun as a light source. But such clear-cut results were not always obtained. On some occasions winkles reached the sides of the dish before finally orientating towards or away from a light source and then the direction of crawling in part became determined by the sides of the dish, for the winkles move along the line of junction of sides and floor.

\section{Winkles collected from vertical surfaces}

It has already been shown that winkles from vertical surfaces make feeding excursions during which they orientate with respect to gravity, but this does not preclude the possibility of reactions to light entering into their responses. Their place of settlement, however, introduces a factor quite different from that affecting winkles on horizontal surfaces, for, since the groynes are opaque, 


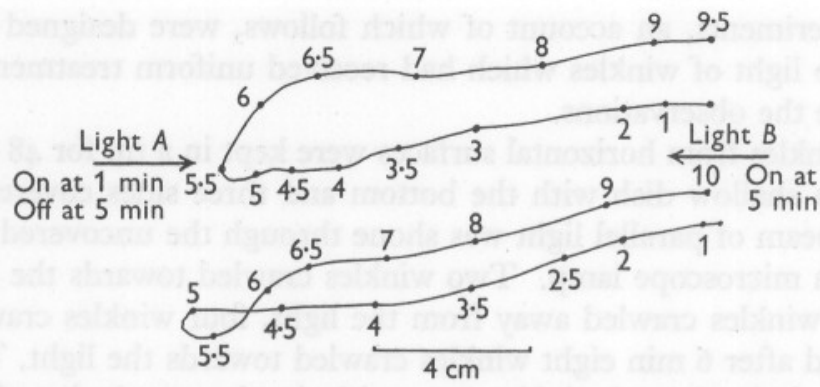

Fig. 2. Tracks of two winkles collected from horizontal surfaces and dark-adapted for 4 days. Numbers along tracks indicate time intervals in minutes. Lights $A$ and $B$ are microscope lamps.

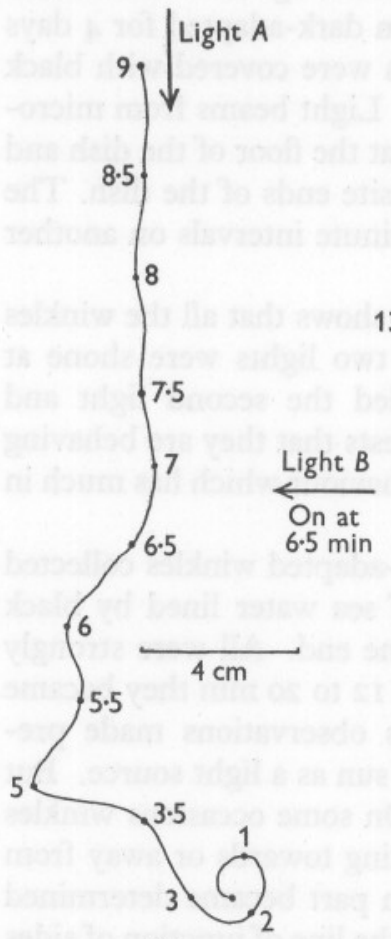

Fig. 3

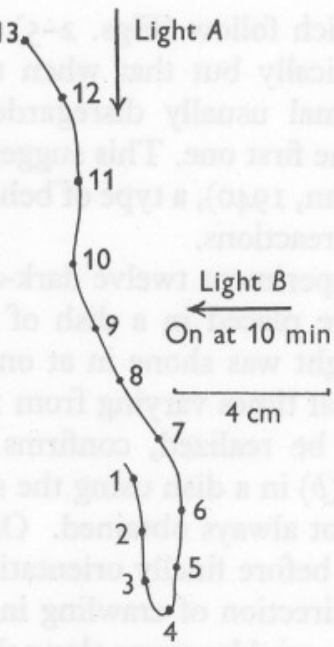

Fig. 4

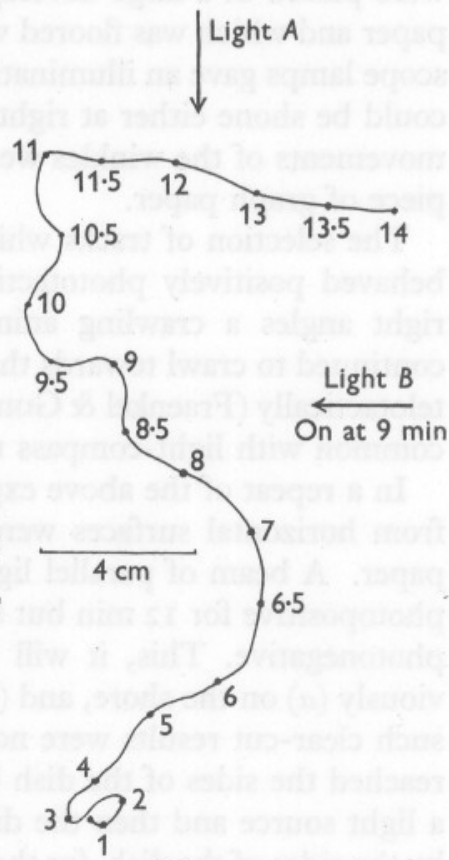

Fig. 5

Figs. 3-5. Tracks of winkles collected from a horizontal surface and dark-adapted for 4 days. Numbers along tracks indicate time intervals in minutes. Lights $A$ and $B$ are microscope lamps.

the incident light must always be mainly from above. It will, however, vary in intensity as the tide rises and falls. When covered to the depth of a metre or more by the turbid water at Whitstable, winkles will be almost in darkness, since even a depth of $\mathrm{I} 4 \mathrm{~cm}$ of water cuts out $95 \%$ of the light reaching the 
surface (Aleem) ${ }^{1}$ and they will become dark-adapted during a period of some hours. As the tide falls the light intensity increases and their behaviour might be expected to vary in a way comparable to that noticed for winkles from horizontal surfaces, viz. they might reverse the sign of their response to light after some time of exposure to higher intensities of illumination. In order to rule out gravitational responses the reactions to light of winkles collected from vertical surfaces were tested by observing their crawling reactions on the floor of a dish.

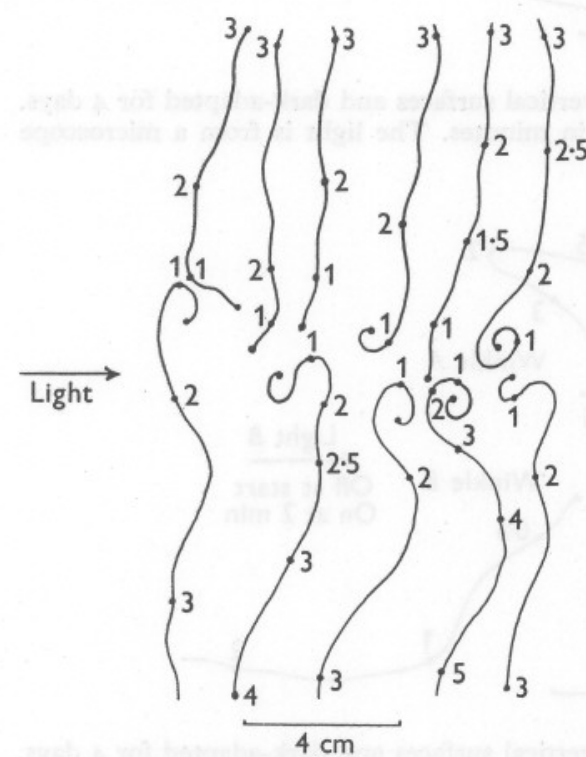

Fig. 6

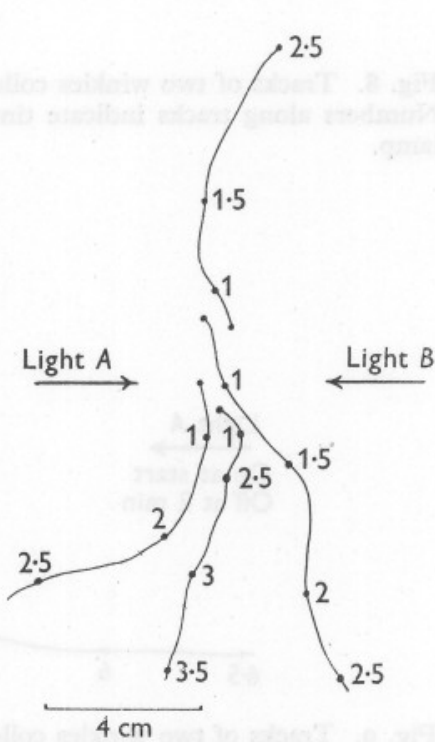

Fig. 7

Fig. 6. Tracks of winkles collected from vertical surfaces and kept in diffuse light for 4 days. Numbers along tracks indicate time intervals in minutes. The light is from a microscope lamp.

Fig. 7. Tracks of winkles collected from vertical surfaces and dark-adapted for 4 days and then exposed to diffuse light for $2 \mathrm{~h}$. Numbers along tracks indicate time intervals in minutes. Lights $A$ and $B$ are microscope lamps.

Numerous observations on the reactions of winkles from vertical surfaces kept in diffuse light for periods of up to several days showed that the animals, when placed in a dish of sea water and illuminated by a beam of parallel light from a lamp, crawled mainly across the light beam. A selection of tracks made under these conditions in given in Figs. 6 and 7.

Fully dark-adapted animals behave somewhat differently. At first most animals crawl away from the light source, but after some time of exposure to illumination they orientate across the light beam, and later still some become photopositive. Some of these responses are shown in Figs. 8-ro.

1 University of London, Ph.D. Thesis, 1948. 


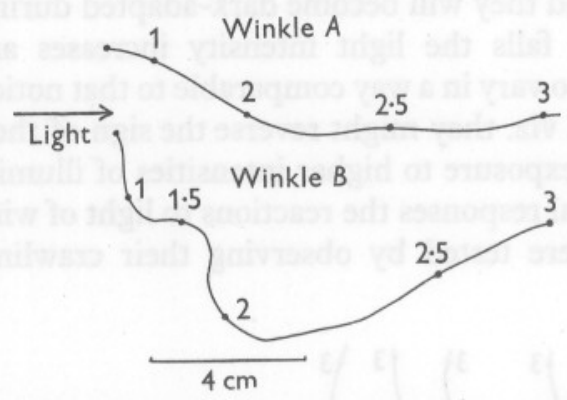

Fig. 8. Tracks of two winkles collected from vertical surfaces and dark-adapted for 4 days. Numbers along tracks indicate time intervals in minutes. The light is from a microscope lamp.

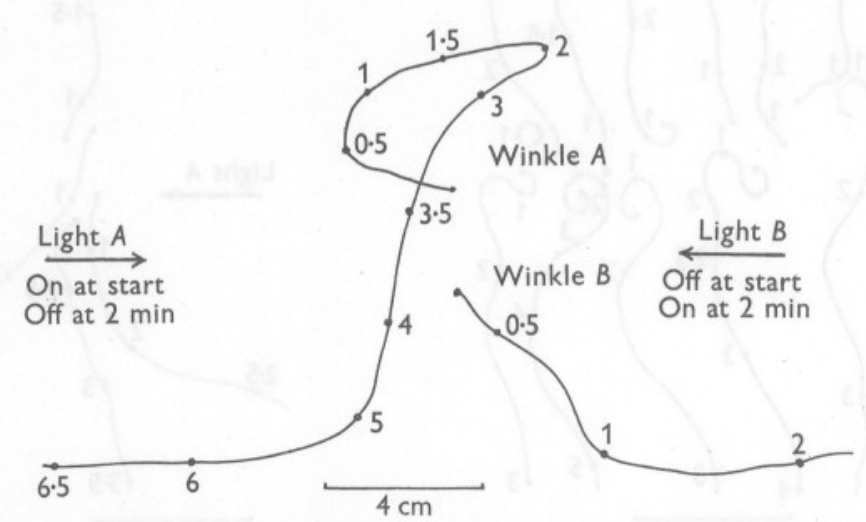

Fig. 9. Tracks of two winkles collected from vertical surfaces and dark-adapted for 4 days. Same two winkles as in Fig. 8. Numbers along track indicate time intervals in minutes.

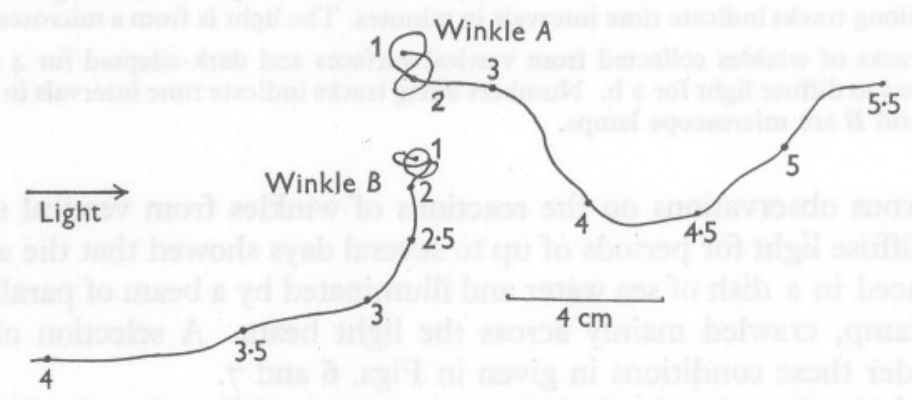

Fig. Io. Same two winkles as in Figs. 8 and 9. Winkle $A$ remained photo-negative but winkle $B$ became photopositive after $2 \mathrm{~min}$ and remained so when repeatedly retested. 
In addition, it should be mentioned that of fifteen winkles collected from vertical surfaces and dark-adapted for $8 \mathrm{~h}$, thirteen were at first photonegative, one was photopositive and one crawled across the light beam. Six which were at first photonegative reversed their direction of crawling after $5 \mathrm{~min}$.

Thus, the feeding migrations of winkles on vertical surfaces are probably, in part, determined by their responses to light. When dark-adapted the animals behave photonegatively, but after a time they orientate across the light beam and they then crawl upwards, having reversed the sign of their response to light. In contrast to winkles from horizontal surfaces, those from vertical surfaces are at first photonegative and their feeding migrations are determined in part by gravity and to a lesser extent by responses to light. Further light is thrown on this point by the observations which follow and which were made to see how winkles behaved when $(a)$ the light stimulus is removed, and $(b)$ when it is acting against gravity.

(i) Dark-adapted winkles from horizontal surfaces were allowed to settle on horizontal glass plates in darkness, when they orientated at random. Viewed in ruby light they crawled, when stimulated by immersion, in a very sluggish fashion and within $5 \mathrm{~min}$ had settled again.

(ii) When twelve dark-adapted winkles from vertical surfaces were allowed to settle in darkness on a vertical glass plate in an empty beaker, all crawled upwards and settled. In ruby light all at first crawled down and then up above the waterline when the beaker was nearly filled with sea water. This shows that in darkness all the winkles when stimulated crawled downwards but that all behaved in a negatively geotactic manner before settling down, although the downward limb of the track was short and the crawling was sluggish.

(iii) The experiment was repeated but with the difference that, when the winkles were submerged, illumination from directly below was provided by a $75 \mathrm{~W}$. lamp. Then eight winkles crawled horizontally, five crawled upwards, two crawled downwards and then up. All settled just above the waterline after $12 \mathrm{~min}$.

This shows that the behaviour pattern which is usual for 'natural conditions' is upset by illumination from below. It also suggests that the winkles which settle on vertical surfaces begin their feeding excursions partially as a negative phototactic response, as probably do also those which have settled on sloping rock surfaces. Other observations on the behaviour of winkles in diffuse light confirm the view that under these conditions they crawl across the light rays. For example, it is the almost invariable rule that winkles placed in a glass aquarium some distance from a north window settle on east and west walls. That is, after a preliminary period of crawling, they ascend and settle on the walls which are not directly facing or away from the light. This behaviour is quite consistent with that observed for the distribution on the beach groynes, on which it is noticed that the vast majority of the animals are clustered against the junction of the vertical posts with the planking. 


\section{Summary of observations on the reactions of winkles to light}

(I) Dark-adapted winkles from horizontal surfaces almost invariably be have positively phototactically but after some time of exposure to a light source they crawl horizontally across the beam and then, later still, behave negatively phototactically.

(2) Winkles from horizontal surfaces kept for some hours in diffuse light usually crawl transversely to a light beam.

(3) Winkles usually, but not always, disregard a second light source when this is switched on after they have orientated to the first source but sometimes they re-orientate towards the second light. They are thus able to behave telotactically to light.

(4) Winkles from vertical surfaces behave to light in a way which in several respects resembles the behaviour of those from horizontal surfaces. Thus, after being kept in diffuse light, they orientate and crawl across the light beam, and reverse the sign of their response when exposed to light after being darkadapted. But there is an important difference, namely that most winkles from vertical surfaces are, when first tested, photonegative.

(5) The behaviour in the laboratory seems to be similar to that noticed on the shore, but suggests that winkles both from horizontal and vertical surfaces carry out feeding migrations which are influenced by light. Those from horizontal surfaces orientate solely by reactions to the direction of light, whilst those from vertical surfaces orientate to the direction of the light (which is always mainly from above) and also to gravity, the two sets of responses normally reinforcing each other.

\section{DISCUSSION}

The results of previous work on the behaviour of littorinids can now be considered, but, as will be apparent, the accounts of shore observations and the results of laboratory experiments on the reactions of winkles to light and to gravity are so conflicting that they give little help in the solution of the problem of the relation of these reactions to observed distribution of Littorina littorea. Indeed, the interpretation of these results is itself an interesting study, since it cannot be reasonably doubted that they are based on accurate, even if incomplete, observations. But the explanations offered in the present paper are at variance with previous accounts. To what, it may be asked, can these discrepancies be attributed? In part the answer is that previous workers failed to take due note of the immediate past history of the animals they studied, the exact situation from which the winkles were collected, the degree of darkadaptation and so on. In part they are due to failure to make continuous observations on individual winkles, with the result that few authors noticed the regularly recurring reversal of the responses to light and gravity and none appreciated their significance in the mode of life of the animals. On the 
other hand, many, if not most, of the observations previously recorded can be confirmed, or partially confirmed, although receiving quite different explanations.

Bohn (1904a) stated that Littorina rudis has a natural rhythm of active and passive life, the whole cycle lasting 15 days, which is due to the varying heights reached by the tides over the lunar cycle. At spring tides the animals are active whilst at neaps the operculum closes and the animals are inactive. This is certainly not true for L. littorea and has not been confirmed for L. rudis. Bohn also stated that this rhythm is retained by $L$. rudis for several months in a laboratory, and he notes that at the time of spring tides the animals become more strongly positively geotactic and phototactic. Bohn (1904b, 1905a) states that on a horizontal surface an animal will crawl towards a light and then later reverse its direction, the time of reversal corresponding with the time at which in nature it would have experienced the maximum degree of dehydration on the shore. Again, referring to 'les littorines', Bohn (1904c) believed that on sloping surfaces winkles orientate along a resultant of the 'forces' due to negative phototaxis and negative geotaxis. Yet, when an animal is upside down on a vertical surface, negative phototaxis is said to be replaced by positive phototaxis. It can be said that these observations have not been confirmed for L. littorea, although, as has been seen, reversal of the sign of the response to light and gravity play a most important part in the feeding excursions. Later, Bohn $(1905 b)$ seemed to show that L. littorea is always negatively phototactic, but, as in previous papers, no details are given of his experimental procedure.

Mitsukuri (190I), working with the Japanese snail, L. exigua, stated that as a rule they are negatively phototactic and that, since the light is always more intense offshore(???), the animals are driven upshore away from the sea. The animals show a 'disinclination' to become submerged, as is shown in an aquarium by raising the water level. This he terms 'negative hydrotaxis'. But, as has been mentioned (p. 248), an exactly comparable behaviour has been seen for L. littorea, for which it is suggested that this is a result of the animals becoming quiescent after the termination of their feeding excursions. Mitsukuri believed that some winkles get left above the waterline but when re-wetted they become positively phototactic and move down the shore. Mitsukuri, it should be noted, paid no attention to gravity responses. Morse (I9IO) believed that his observations showed that $L$. littorea is negatively phototactic during the daytime in June but becomes positively phototactic as night approached. But, after I8 June, the numbers of winkles behaving in a positively phototactic manner predominated even during daytime, whilst the period of transition of the light responses corresponded with the time of change from spring to neap tides during which time winkles in a natural state on the rocks were exhibiting a corresponding change in phototaxis because the tide did not reach them. Morse therefore believed that he had confirmed the 
observations of Mitsukuri who stated that winkles, when desiccated, become positively phototactic and when submerged negatively phototactic. It is to be noted that Morse overlooked any possible reactions to gravity and that he gave no description of his experimental procedure. Haseman (I9II), working on L. littorea at Woods Hole, was unable to confirm Bohn's results on tidal rhythmicity. He observed that winkles placed on horizontal surfaces do not show rhythmical movements corresponding with the rise and fall of the tides, but that snails located on more or less vertical surfaces follow the surface film of the water as it is raised or lowered. I have not been able to confirm this, but as has been stated (p. 248) winkles after a quiescent period crawl down and then up again to settle at or near the surface of the water. One curious observation which may be mentioned is that the winkles with which Haseman worked stopped opposite olive-green sectors in an aquarium in preference to sectors coloured yellow or brown. Haseman explained the zonation of winkles at Woods Hole along the following lines. Submerged animals crawl at random but do not crawl on dry surfaces and are not found above tidemarks. As the tide rises some, by mere chance, crawl above the waterline but the dryness and unevenness of the surface slows them down so that the tide overtakes them and they become submerged. When the tide falls, a few may get left behind and cling to the rocks.

Kanda (I9I6) also made studies on L. littorea and pointed out that earlier workers had omitted to take into account reactions to gravity. When winkles were allowed to crawl on a glass plate submerged in water he found that the steeper the angle of the plate, the greater was the number of negatively geotactic animals, but even on slopes as gentle as II degrees, $55 \%$ of the animals were negatively geotactic whereas, at angles of 90 degrees, $100 \%$ were negatively geotactic. Similar results were got with winkles crawling on a plate in air, but when a ground-glass plate was used $15 \%$ of the specimens behaved positively geotactically even at slopes of 90 degrees. Kanda interpreted this to mean that winkles tend to become positive when dry and points out that this 'would evidently serve as a protective reaction when they are left by the retreating tide'. When Kanda's results are examined in detail the striking thing is the irregularity of the gravity responses. For example, when a wooden plate was substituted for a glass one, in air, at an angle of 90 degrees, $52 \%$ of the winkles were positively geotactic, $16 \%$ were negative whilst $15 \%$ crawled horizontally. The rest fell off the plate.

The result of this experiment, which was made in darkness, was interpreted to mean that positive geotaxis predominated, but since Kanda failed to notice the reversal of the sign of the response to gravity the difference in the result from that of previous experiments may well have been due to the circumstance that he was observing downward, horizontal and upward parts of $U$-shaped tracks now known to be typical of winkles on vertical or steeply sloping surfaces at Whitstable. In nature Kanda thought that 'the limitation of upward 
movement is due chiefly to the exhaustion of moisture carried by the foot from the sea. They seldom, if ever, crawl on dry rocks much higher than high tide mark.... They seem to stop crawling when the moisture which they carry themselves is exhausted.' When tested under similar conditions, except that the apparatus was half-filled with water with the plate at 90 degrees, no winkles were positively geotactic but twelve out of I 50 crawled horizontally on reaching the surface film. In direct sunlight with the light parallel to the plate the winkles which were 'negatively heliotropic' showed a variety of reactions: 10 $\%$ crawled diagonally, I6\% went horizontally whilst $74 \%$ crawled downwards, so that both light and gravity seem to affect the direction of travel. Discussing these results and those of previous workers, Kanda states that L. littorea is, as believed by Bohn $(1905 a, b)$, 'negatively phototropic'. Indeed, Kanda places great emphasis on this point which, he says, is 'the unmistakable reaction of the animal to light'. Winkles (he says) do not, as supposed by Morse, crawl upwards because of 'positive heliotropism' but on account of 'negative geotropism', and in spite of 'negative heliotropism', and he further believes that Morse's view that as night approaches winkles become increasingly positively phototactic is incorrect. Haseman's results also come in for criticism by Kanda who (quite correctly) says that they are not clearly set out and that no account was taken of possible reactions to the sun's rays. Here again, it may be remarked, Kanda failed to notice the regular reversal of responses to light.

Gowanloch \& Hayes (1926) were primarily concerned with the behavioural features affecting the zonation of $L$. littorea on a rocky shore. They state that winkles are never found on areas of fine sand or mud but are typically inhabitants of exposed rock surfaces, from which it is obvious that their remarks do not apply to the many situations other than rocks where winkles flourish. They believed that, although not expressible in a quantitative way, their observations on marked winkles showed that the animals returned to a particular tidal level when displaced. No evidence for this has been found in the present investigation. Their results also seemed to show that winkles varied in the degree of their response to light and to gravity. Those collected from high up on the shore are more strongly positively phototactic than those from lower down and desiccation steadily increases the degree of 'negative geotropism'. Later (1929) Hayes presented evidence for the view that increasing the time during which winkles are desiccated decreases the degree of 'negative geotropism' and that, conversely, prolonging the time of immersion increases 'negative geotropism'. Colman (1933), in a valuable discussion of the factors underlying zonation, pointed out that 'the combined effect of these reactions is to make it difficult for each species to get away from its normal habitat'.

This may well be true, but, as has been mentioned (p. 25I), these differences in behaviour were probably caused not by differences in shore level as such 
but by variations in the steepness of beach slope, the lower levels being less steep than the upper ones.

On the flat type of shore, such as the 'wattens' and 'waddens' of the north German and Danish coasts, Schwarz (1932) stated that gravity responses play little or no part in the orientation of the winkles found there. When the sun is low and the light is directional, winkles behave positively phototactically when uncovered by the tide. Thus, they move from east to south in the morning and from south to west in the evening. On dull days and when the sun is high in the sky they move in a random manner. Ankel (1936) was unable to confirm what he terms 'this remarkable finding', yet had Schwarz noticed the reversal of the direction of crawling, his observations would have been substantially correct.

Reference may be made to papers dealing with the behaviour of species of Littorina other than littorea. Fraenkel (1927) carried out a thorough investigation of the reactions of $L$. neritoides to light and to gravity and convincingly showed that when submerged the animais are photonegative except when upside down (as when crawling on the ceiling of a rock crevice) when they are photopositive. Moreover, they are usually geonegative and so tend to crawl up rock faces. These reactions serve to explain why $L$. neritoides moves to the upper shore and splash zone. If when moving under water an animal encounters a crevice its negatively phototactic behaviour takes it inwards along the floor; its negative geotaxis causes it to climb the end wall and brings it to an upside-down position when it behaves positively phototactically and crawls along the ceiling out of the crevice. Yet when out of water, as when its movements have brought it above the tidal level, upward crawling is continued and if it enters a crevice as a result of negative phototaxis, it stays there, for the sign of this response does not reverse until the animal becomes submerged. This analysis goes a long way to explain the observed distribution of $L$. neritoides, which commonly inhabits crevices near and even above H.w.S., but that it is incomplete is shown by the observations (Lebour, 1935; Lysaght, 194I) that the animals are sometimes found in numbers in situations where they are permanently submerged. Moreover, at whatever tidal level it is found, L. neritoides must, presumably, leave its crevice on occasions in order to feed. It must be supposed, therefore, that the behaviour of this winkle is less stereotyped than Fraenkel's account would indicate.

A recent paper by Barkman (1955) deals with the reactions of $L$. obtusata. He states that this species is negatively geotactic and that this agrees with the results of all previous observers of littorinids except Mitsukuri (I90I) and Morse (1910). L. obtusata is also invariably negatively phototactic. Barkman could detect no tidal rhythms and found that in a tank with a sloping floor and with an arrangement for simulating a rising and falling tide with an oscillation of $33 \mathrm{~cm}$, the animals came to rest at about $6 \mathrm{~cm}$ above the waterline. This he explained by assuming that winkles have a tendency to crawl 
upwards until halted by desiccation. Similar movements occur on the shore, it is said.

The view of the locomotory pattern of behaviour of the common winkle, L. littorea, presented in the present paper, reduces the responses to a rather simple but reversible reaction to the direction of the incident light, which can be reinforced by gravity responses. All the winkles seem to spend most of the time in which they are submerged by the tide or exposed to the air, settled on places which offer good holding ground. But when stimulated, as by increased wave action during a rising or falling tide, they are activated and make feeding excursions of limited duration out from and back to their approximate place of settlement, thus tracing out roughly $U$-shaped tracks on the substratum, whether it be the sand or the vertical face of a groyne. The physiological explanation for the reversal of the sign of responses is not known, but, since it occurs even when the external environment is maintained constant, as under laboratory conditions, it must depend on some internal mechanism, and, following Pittendrich (1956), this may be termed a biological clock but one which does not fall readily into any one of the categories he specifies.

On very flat shores, such as occur in the Whitstable area, only two types of situation are (apart from very occasional small boulders) available for winkles to settle on, viz. the practically flat beach and the vertical surfaces of groynes, but on rocky shores winkles are presented with surfaces which have a great variety of slopes. It is highly likely, therefore (and preliminary observations at Plymouth reinforce this view), that the behaviour of winkles on rocky shores is more complex than that on flat shores in the sense that their feeding excursions are always determined in part by the direction of the light and in part by gravity, the two stimuli varying in importance according to the position of settlement, whereas, as has been seen, dwellers on flat surfaces orientate solely in response to light and those on vertical surfaces mainly in response to gravity.

The ecological importance of this type of behaviour would seem to be that a mainly sedentary animal is able to maintain its station of the shore in a position of security, but also, by reacting to environmental clues, to move out and return to a place of settlement, feeding meanwhile. The kind of behaviour exemplified by winkles finds a more precise expression in the movements of other intertidal animals, of which the common limpet, Patella vulgata, may be singled out for comment. Here the feeding excursions, which have repeatedly been described, end with a return to an exact spot or scar on the rock from which the animal began its crawl. Limpets can be truly said to return to a home. But it cannot for a moment be supposed that this type of behaviour, although outstanding in its precision, is unique. Rather it would seem proper to regard it as the extreme of a series at one end of which are intertidal animals that wander 'at random', and at the other those which regularly leave and return to a strictly localized spot. Winkles seem to occupy 
an intermediate position in this series and are, perhaps, representative of the vast majority of shore animals, although this is not to say that the environmental clues selected and the reactions to them are identical in all instances. Some, indeed, are unexpectedly complicated. For example, Papi \& Pardi (I953) and Pardi \& Papi (I953) showed that Talitrus saltator makes excursions after emerging from the sand and orientates by means of a light-compass reaction, moving up and down the beach at right angles to the shoreline, no matter what the time of day, and so returning to the zone of moist sand. This implies that in some way the animals make allowance for time in fixing their angle of orientation to the sun.

There can be little doubt that, as stressed by Ewer (1956), the distribution of animals on the shore is a dynamic process initiated by larval behaviour and in some instances maintained by the behaviour of the adults.

Winkles are structurally adapted in several obvious ways to life in the intertidal zone, to which, indeed, they are virtually restricted, few if any occurring below E.L.w.S. even when the nature of the sea floor is suitable and food is abundant. Bearing in mind that L. littorea can withstand prolonged immersion-for more than 50 days (Hayes, 1929) - the reasons for a fairly sharply defined lower limit to the zonation are obscure, whereas, other considerations apart, inability to withstand continued exposure and lack of suitable food suffice to account for the upper limit at approximately H.W.N. The results of the present investigation suggest that the lower limit of zonation may be that at which there is too little mechanical disturbance and too low a level of light intensity to stimulate winkles to embark on the feeding excursions, so that any which by chance settle below tidemarks are by their behaviour inhibited from feeding and so fail to become established.

\section{SUMMARY}

Winkles dwelling on horizontal surfaces orientate by means of a lightcompass reaction. As the tide recedes, most of the tracks in the sand are towards the sun but after a time each animal reverses its direction of crawling, so tracing out a roughly $U$-shaped path which leads it back, approximately, to its starting-point.

When kept in an aquarium winkles tend to settle on the sides above the waterline and to become inactive. When stimulated, as by immersion, they crawl downwards, then horizontally and then upwards before settling above the waterline.

Winkles collected from horizontal surfaces at first show no tendency to climb vertical surfaces in an aquarium. After a period which varies from a few hours up to Io days they do climb the sides of the tank. Animals collected from vertical surfaces climb the sides of the aquarium at their first opportunity and then settle. It can be concluded that winkles have an inherent tendency to 
climb and settle in the head-up position on vertical or steeply sloping surfaces but that if this opportunity is denied them they become habituated to horizontal surfaces.

The minimum angle to which winkles can react by gravitational responses is of the order of 10-20 degrees.

In an aquarium starved winkles prolong their excursions below water when presented with suitable food but fully fed animals respond less strongly to the stimulus of immersion.

Dark-adapted winkles from horizontal surfaces are at first positively phototactic, but after a time varying from I5 to $20 \mathrm{~min}$, they become negatively phototactic. Tested with the 'two-light' experiment most animals disregard the second light (telotaxis).

Dark-adapted winkles from vertical surfaces are at first negatively phototactic and then from periods of $5 \mathrm{~min}$ and upwards photopositive. This behaviour agrees with that seen on the shore, where their feeding migrations are orientated responses to gravity but are reinforced by reactions to light.

The relations of the responses of winkles to light and to gravity to the observed pattern of zonation are discussed.

\section{REFERENCES}

ANKeL, W. E., I936. Prosobranchia. Tierwelt N.-u. Ostsee, Teil 9, b, 240 pp. (Lief. 29). BARKMAN, J. J., I955. On the distribution and ecology of Littorina obtusata (L.) and its specific units. Arch. néerl. Zool., T. II, pp. 22-86.

BoHN, G., I904a. Periodicité vitale des animaux soumis aux oscillations du niveau des hautes mers. C.R. Acad. Sci., Paris, T. 139, pp. 6ro-II.

- I904b. Oscillations des animaux littoraux synchrones de la marée. C.R. Acad. Sci., Paris, T. 139, pp. 646-8.

- r $1904 c$. Influence de la position dans l'éspace sur les tropismes. C.R. Soc. Biol., Paris, T. 57, pp. 35I-3.

- I905a. Attractions et oscillations des animaux marins sous l'influence de la lumière. Mem. Inst. gén. psychol., T. I, pp. I-III.

— I905b. L'éclairement des yeux et les mouvements rotatoires. Essais et erreurs dans les tropismes. C.R. Soc. Biol., Paris, T. 59, pp. 564-7.

Colman, J., 1933. The nature of the intertidal zonation of plants and animals. F. mar. biol. Ass. U.K., vol. 18, pp. 435-76.

Ewer, D. W., 1956. Animal ecology and behaviour. S. Afr. F. Sci., Vol. 52, pp. 21 II5.

FraENKEL, G., 1927. Beiträge zur Geotaxis und Phototaxis von Littorina. Z. vergl. Physiol., Bd. 5, pp. 585-97.

Fraenkel, G. \& GunN, D. L., 1940. The Orientation of Animals, Kineses, Taxes and Compass Reactions. Oxford.

Gowanloch, J. N. \& HAYES, F. R., I926. Contributions to the study of marine gastropods. I. The physical factors, behaviour and intertidal life of Littorina. Contrib. Canad. Biol., N.S., Vol. 3, pp. 135-65.

HASEMAN, J. D., I9II. The rhythmical movements of Littorina littorea synchronous with ocean tides. Biol. Bull., Woods Hole, Vol. 2I, pp. II3-2I. 
Hayes, F. R., 1929. Contributions to the study of marine gastropods. 3. Development, growth and behaviour of Littorina. Contrib. Canad. Biol., N.S., Vol. 4, pp. 4r3-30.

KANDA, S., I916. Studies on the geotropism of the marine snail, Littorina littorea. Biol Bull., Woods Hole, Vol. 30, pp. 57-84.

Lebour, M., I935. The breeding of Littorina neritoides. F. mar. biol. Ass. U.K., Vol. 20, pp. 373-8.

Lysaght, A. M., I94I. The biology and trematode parasites of the gastropod, Littorina neritoides (L.) on the Plymouth breakwater. F. mar. biol. Ass. U.K., Vol. 25, pp. 4I-63.

MITSUkURI, K., I90I. Negative phototaxis and other properties of Littorina as factors in determining its habitat. Annot. zool. Fap., Vol. 4, pp. I-I9.

Morse, M. W., I9IO. Alleged rhythm in phototaxis synchronous with ocean tides. Proc. Soc. exp. Biol., N.Y., Vol. 7, pp. 145-6.

Newell, G. E., 1954. Animal zones on the North Kent Coast. S. East. Nat., Vol. 59, pp. $34-56$.

- 1958. The behaviour of Littorina littorea (L.) under natural conditions and its relation to its position on the shore. F. mar. biol. Ass. U.K., Vol. 37, pp. 229-239.

PAPI, F. \& PARDI, L., I953. Ricerche sull' orientamento di Talitrus saltator (Montagu) (Crustacea Amphipoda). 2. Sui fattori che regolano la variazione dell' angolo di orientamento nel corso del giorno. L'orientamento di notte. L' orientamento di un altro populazione. Z. vergl. Physiol., Bd. 35, pp. 490-518.

PARDI, L. \& PAPI, F., I953. Ricerche sull' orientamento di Talitrus saltator (Montagu) (Crustacea Amphipoda). I. L'orientamento durante il giorne in una populazione del littorale tirrenico. Z. vergl. Physiol., Bd. 35, pp. 459-89.

PitTENDRICH, C. S., 1956. Perspectives in the study of biological clocks. Perspectives in Marine Biology. University of California Press.

SchwarZ, S., 1932. Der Lichteinfluss auf die Fortbewegung, die Einregelung und das Wachstum bei einigen niederen Tieren, (Littorina, Cardium, Mytilus, Balanus, Teredo, Sabellaria) Senckenbergiana, Bd. I4, pp. 429-54.

Stevens, G. C., Fingerman, M. \& Brown, F. A., I953. The orientation of Drosophila to plane of polarized light. Ann. ent. Soc. Amer., Vol. 46, pp. 75-83.

Thorpe, W. H., 1956. Learning and Instinct in Animals. London: Methuen.

WIIsON, D. P., 1929. A habit of the common periwinkle (Littorina littorea Linn.). Nature, Lond., Vol. 124, p. 443. 